\title{
Analysis of Western Wooden Structure Technology's Influence on Yangzhou Wooden Architecture in Modern Times
}

\author{
Jianxin ZHANG \\ College of civil science and engineering \\ Yangzhou University \\ Yangzhou, P.R.C. \\ e-mail: sdjz9999@163.com
}

\author{
Yan LIU \\ College of civil science and engineering \\ Yangzhou University \\ Yangzhou, P.R.C. \\ e-mail: liuyan@yzu.edu.cn
}

\begin{abstract}
This paper summarizes the differences between Chinese and Western wood construction technologies on the basis of reviewing the development of Chinese and Western wood construction technologies, and tentatively analyses some cases of the influence of Western traditional wood construction on Yangzhou modern architecture and the causes in society, economy and culture. It points out that to develop future wood construction technology, the fundamental way out lies in introducing, integrating, absorbing and developing Western wood construction technology, and in the combination of science and experience.
\end{abstract}

Keywords-western wood construction technology; Chinese wood construction technology; church architecture; Yangzhou modern architecture

\section{INTRODUCTION}

The wood construction architecture had a history of more than three thousand years in Ancient China. Wood construction was used in from palaces, temples and gardens, to prince's palaces, vernacular dwellings and folk public buildings. During the long history of the development, some changes happened in the order of building components, but such changes were not fundamental. Tailiang System, Chuandou System and Jinggan System are all accumulations of construction experience, so there haven't happened any revolutionary breakthrough. Compared with Western construction, traditional Chinese wood construction architecture is wasteful in materials. Besides, the unitary construction shape could not satisfy the needs of the social development of modern times. However, in the West, with the scientific development and progress, not only traditional wood truss technology, but also wood construction dwelling technology have developed from experience to science, which has become the mainstream of global contemporary wood construction development.

\section{THE INFLUENCE AND ITS CAUSE}

Yangzhou city has an urban history of about 2500 years, and is among the first group of 24 historic cities authorized by the government of China. It had been one of the central cities in economy and culture in the history of China. Benefiting from the canal transportation and the accumulation of wealth obtained through salt business, the urban construction, dwelling and garden construction were on a high level, so Yangzhou traditional wood construction technology remained comparatively mature. Until now there still exist old buildings of about 500,000 square meters of Ming dynasty, Qing dynasty and Republican China, among which about 6000 have been maintained well. Some buildings of high historic value, artistic value and academic value has been classified into different levels of cultural relics unit protection, including 16 national key cultural relics protection units, 21 provincial level cultural relics protection units, 171 municipal culture relics protection units and 37 historic architectural buildings. These traditional buildings mainly adopted traditional Chinese wood construction technology, but among a few traditional buildings in modern time, there existed obvious Western wood construction technology influence.

\section{A. The Reflection of the Influence}

First of all, the influence is embodied in the complete transplant of Western traditional wood construction technology to Church architecture in Yangzhou.

One example is Western Style House, No.6 in Xiapu Street which was built by American missionary Pierce. It is a two-story house and its space layout completely abandoned the cohesive type of space layout of the house with four-side enclosed courtyard, and adopted outward oriented space layout with windows on four sides respectively. The roof supporting structure is Western primary beam triangle wood truss which is comparatively steep. (Fig.1)

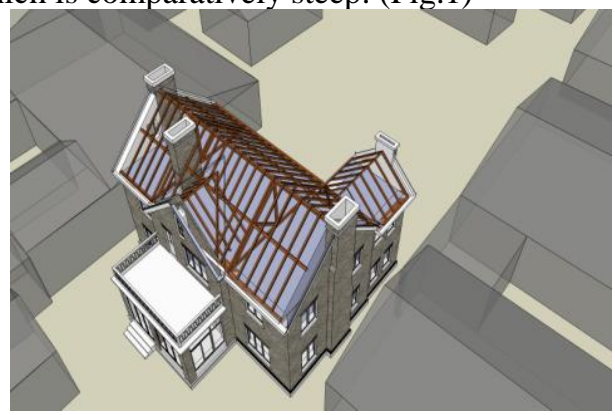

Figure 1. Western style house, No.6 in Xiapu Street (built in 1892)

The second example is Mu Jiuli Renai Building. Mu Jiuli Elementary school was a typical church school in Yanghzou, and now is Yangzhou Yucai Elementary School. The school was established by $\mathrm{Ms} \mathrm{Mu}$ Jiuli in 1888. Renai Building which has been preserved well is an H-shaped two-story 
building with brick-wood construction. Built in Guangxu Period, Qing dynasty, it is of typical Gothic revival and Roman style with large architectural volume. The roof structure is steep wood truss, with a span of 13 meters. What is special about top wood truss is that the bottom chord can be designed as the ground, which provides usable region for top space. (Fig.2)

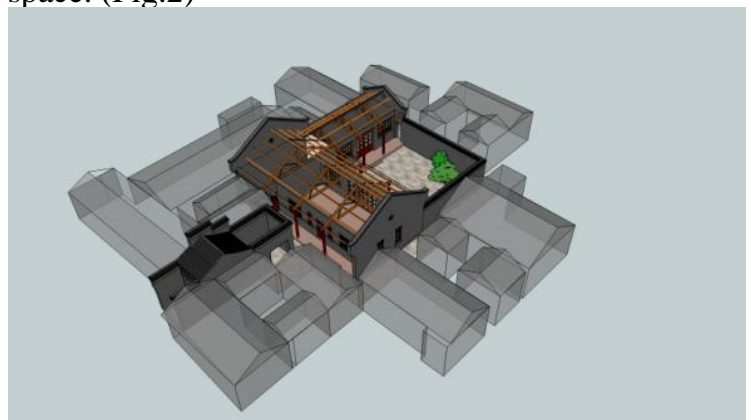

Figure 2. Xu house, No.97 in Dongguan Street (built in Minguo period)

The third example is Emmanuel Church which was located on Yanfu Road Campus of Yangzhou University and was built in the 13th year of Minguo period. It is a chapel of typical Gothic revival and Roman style covering an area of 800 square meters and with a total floor area of 500 square meters. The roof structure is comparatively deep wood truss of the Chinese character “人” shape and hammer shape and with a span of 9.6 meters. (Fig.3)

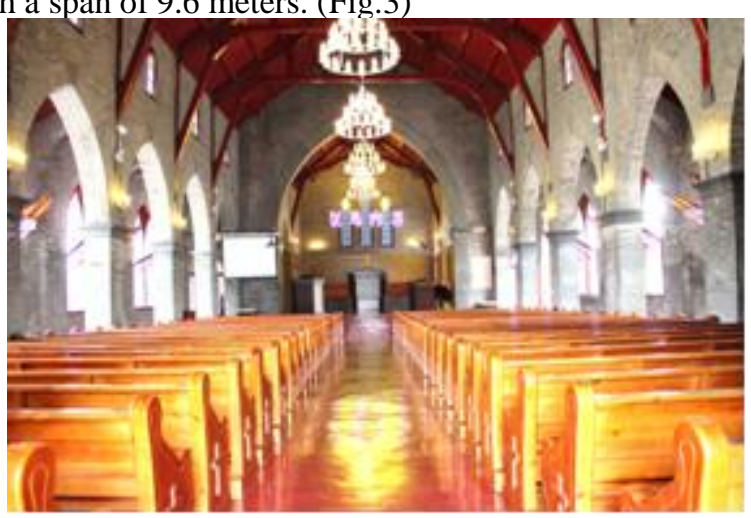

Figure 3. Emmanuel church (built in 1924)

Secondly, the influence of modern Western construction technology on Yangzhou traditional wood construction technology is also embodied in the combination of Chinese and Western wood construction technologies. Many Yangzhou traditional buildings in Minguo Period still inherited Chinese traditional wood construction, the truss of which used Western modern wood truss technology. An example is the remaining gatehouse and a row of rooms of the Xu Residence, No.97 in Dongguan Street, with the north main gate facing Dongguan Street. Entering the main gate with brick carving, a row of three rooms are large in volume, with the depth of nine purlins and corridors on both the north and the south sides. The truss in the middle is the typical Howe Style triangle wood truss with a span of 9 meters. (Fig.4)

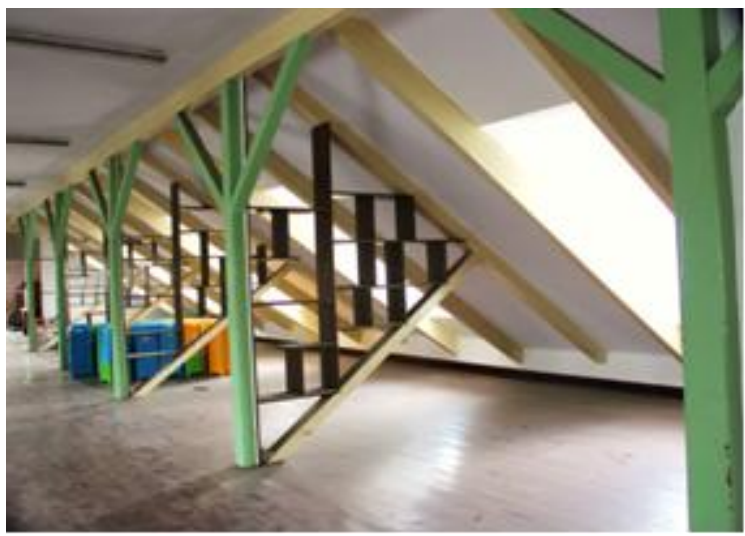

Figure 4. Church school (built in 1888)

Thirdly, Western technology was actively used in modern business, service and industrial buildings. Because they need continuous lower story large space or multi-story large space, and even with clerestory on the roof, these buildings usually gave up traditional wood frame construction, but used masonry-timber structure, that is, with brick wall and brick volume holding the weight in the outside, with wood volume, wood beam and wood floor in the inside, and with Western wood truss on the roof.

One example is Yangzhou Bathhouse in Suchang Alley. The bathhouse was constructed in 1928 by Yuan Bingnan, a man from Shanghai, covering an area of 1700 square meters. The building faces south with a hipped roof. The Douglas fir wood was imported from America. Yangzhou bathhouse was built approximately a hundred years ago, but the structure has remained unchanged. The skylight of Yangzhou bathhouse can make bathers enjoy natural light. The skylight not only releases light in summer, but brings warm sunlight to bathers in cold winter. The supporting structure of skylight is Western traditional main beam wood truss with a span of 3 meters. (Fig.5)

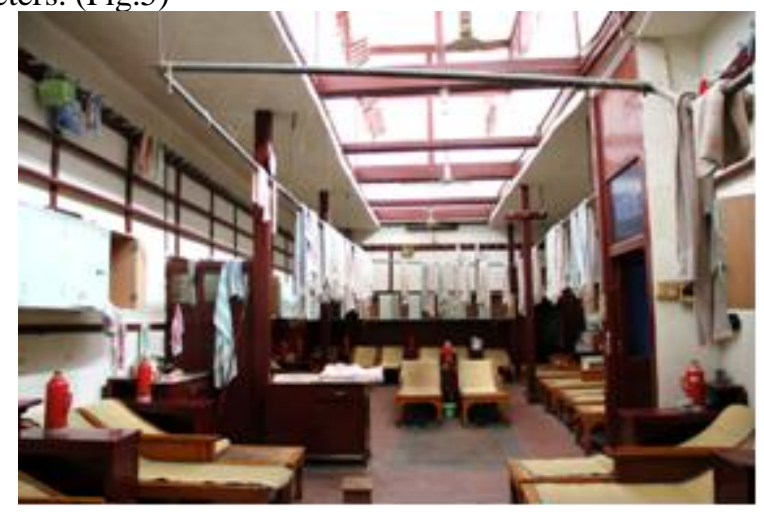

Figure 5. Yangzhou Bath House (Built in 1928)

The second example is Jiyuan Inn in Sanyige Street. The space layout is a two-story building surrounding a traditional Chinese courtyard. The main structure of the building is traditional Chinese wood construction, while the roof structure of clerestory over the yard is Western Howe Style wood truss with a span of 6 meters. (Fig.6) 


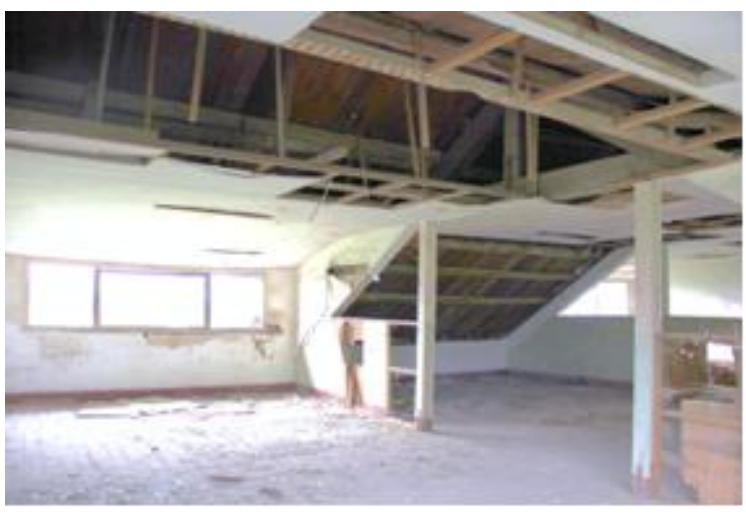

Figure 6. Workshop of Yangzhou seed station (built in 1917)

The third example is Yangzhou silkworm mill which was originally located in No. 5, Wutaishan Road, Erbanpu Community, and built in the 16th year of Minguo Period (1937). The total floor area is 1817.2 square meters. It faces south, with 8 rooms in a row, a depth of 13.05 meters, and a suspension roof. There are three floors on the ground and one floor underground. The roof structure is triangle truss with a span of 13 meters. What is special about top wood truss is that the bottom chord can be designed as the ground, which provides usable region for top space, and this truss is similar to the wood truss of Mu Jiuli Elementary School. (Fig.7)

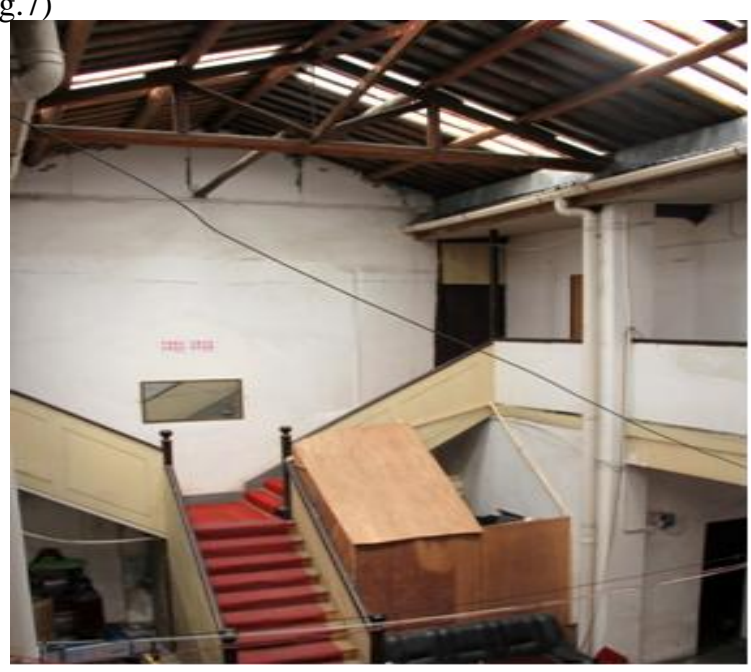

Figure 7. Jiyuan Inn (built in 1912)

The fourth example is the new industry architecture after the establishment of new China. The two wood construction factory workshops of Yangzhou Bus Manufactory in Dujiang South Road were built in 1958 with the main span of 12 meters and 18 meters respectively, and the roofs adopted typically modern Howe style triangle wood truss. (Fig.8)

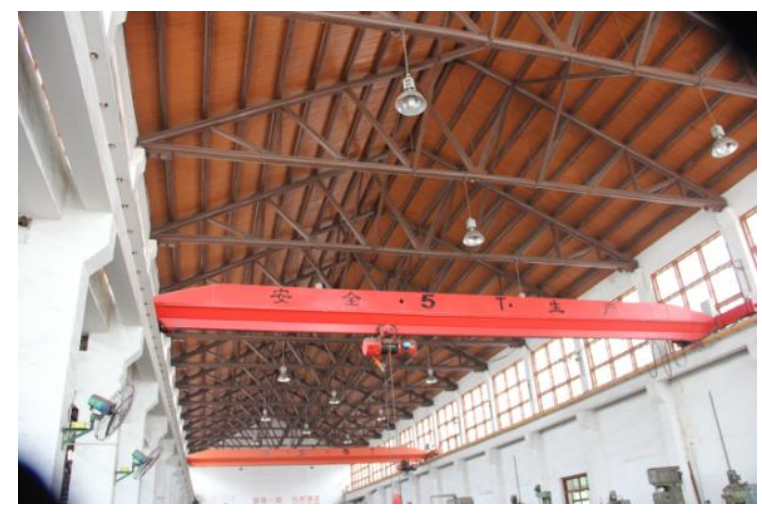

Figure 8. Wood construction factory workshops of Yangzhou bus manufactory (built in 1958)

Finally, there is the influence of Western wood construction on decoration details, such as hanging fascia, the stair rail, and the corridor rail.

A case in point is the wood construction decoration details in The Garden of Yangzhou. He Garden was initially built in 1883. Its main characteristic is the combination of Chinese and Western styles which is especially embodied in two buildings, Xuchun Hall and Yuxiu House in He Garden. The Western influence in wood construction decoration details appeared in following aspects: the stand bar and corridor volume connection, the beautiful curve of which shows the visual effects of continuous arch in Western architecture. The diameter and height of corridor pillars and the wood quality are comparatively small. So compared with the massive European rock pillars, they appear to be slender and agile. The second is the door, which is different from that of traditional residence in China. The upper part of the door is curve brick, and magnolia flower fence curve window. The traditional Chinese grid glass door is covered by wood screen door. The third is the window. The grid glass window is covered by wood screen window and on top of the window is the curve brick arch, but on top of the arch is traditional Chinese think brick frame window, which is in harmony with the arch. The fourth is the railing. The railing of Yuxiu building is the vertical beading, and all the beads are of the same size and look round and shiny [1]. (Fig.9)

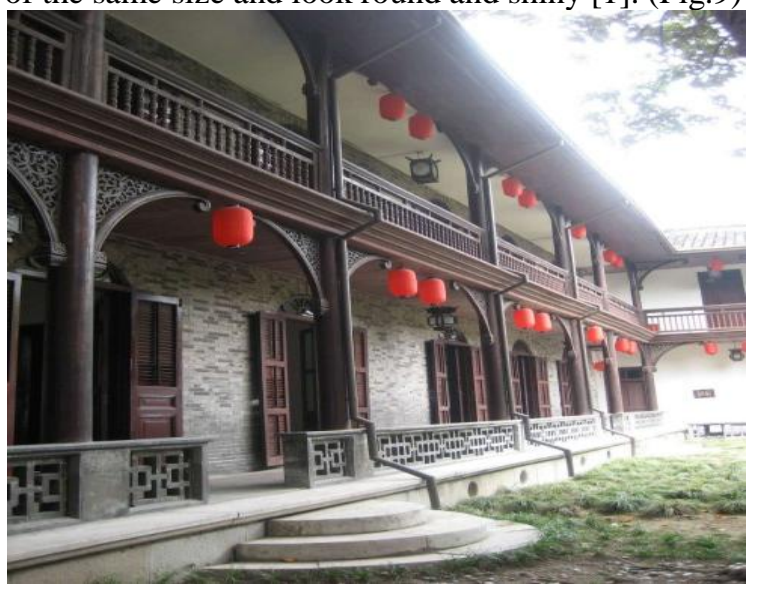

Figure 9. Yuxiu house in He garden (built in 1883) 


\section{B. Analysis of Cause}

The causes of the Western influence on Yangzhou modern wood construction can be divided into political, cultural, economic and technological causes.

The first cause is Church culture. Architectural historians think that it was initially through church culture that early Western architecture influenced Chinese modern architecture. The influence of Western missionaries' on Yanghzou architecture was obvious, such as church hospital, church school, church and missionary dwellings. Though the remaining church buildings are small in both numbers and size, the quality is good, and the buildings are still in use today, and have become a very important part in the remaining architecture in Yangzhou.

A very interesting case of Western influence is The Christian Truth Church in Beiliu Alley which was built in 1934. The main gate faces the west towards Bailiu Alley with gablet roof. The architectural design and shape adopted traditional Chinese gablet roof shape, and only the main entrance was changed into gable entrance and the main gate was changed into the Gothic pointed arch transparent door. The church was built by missionaries sent by Pentecostal churches in America, the architectural style of which is significant to the study of how Christian architecture was localized in Minguo Period. The architecture form and appearance are apparently localized, but the interior supporting roof is still Western main beam triangle truss with a span of 9 meters. (Fig.10)

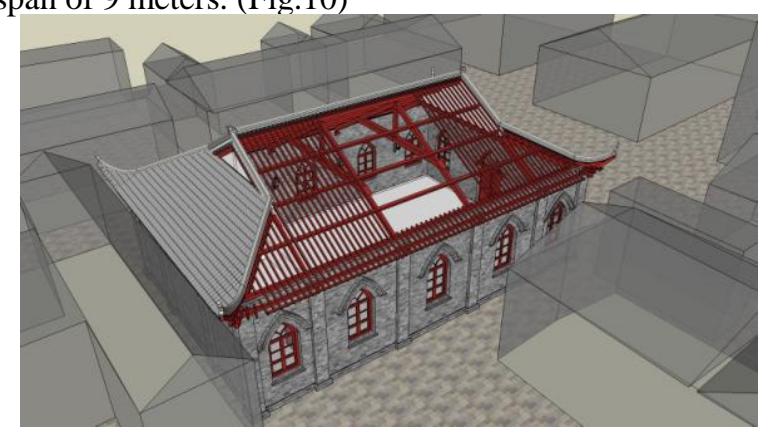

Figure 10. Christian truth church (built in 1934)

The second cause is the influence of Western style architecture of Shanghai on Yangzhou architecture. Yangzhou was not an open city, and Western culture couldn't directly influence Yangzhou architecture, while from Shanghai, Yangzhou architects absorbed some methods of Western architecture in a certain degree, including brickwood structure, especially wood truss roof system of modern West. Typical cases are Yangzhou bathhouse, Yangzhou Luyang hotel and Yangzhou Dalu hotel.

The third cause is the advocating of Westernization Group. For example, the combination of Western and Chinese styles in He Garden was closely connected with the Western Group identity of the garden owner He Zhidao. Firstly, He family and the government official Li Hongzhang and the teacher of Emperor Guangxu are related by marriage. Besides, He Zhidao had worked as the supervisor of Jianghan Customs for eight years. Finally, He family were doing business in Shanghai, so it is not surprising that the garden combined both Chinese and Western architectural styles.

The fourth cause is the government's mandatory advocating. After the establishment of new China, the construction speed was fast. Because wood construction is easy to make and construction materials could be obtained from local places, a lot of brick-wood structure buildings have been constructed [2]. At the same time, the wood roof construction technologies of modern West have been made into technological standards and design models, so naturally, a great amount of industry architecture has adopted advanced Western wood truss technology.

\section{CONCLUSION}

Traditional Chinese wood construction has its limitation in providing large space without pillars, while Western wood truss construction technology has its advantage in this aspect. Therefore, the influence of Western wood construction on Yangzhou modern wood construction architecture is mainly embodied in the use of the large span wood truss.

Compared with Yangzhou traditional wood construction technology, Western brick-wood construction technology saves wood because load bearing brick walls have replaced wood pillars and wood beams, which is the main reason the government and some experts accept Western construction technology.

Western construction parts and decoration parts were appreciated by Yangzhou people from different backgrounds because of their Western style, which might be a very important reason why Yangzhou modern architecture was influenced by Western architecture even though Yangzhou was not an open city.

\section{FUTURE OUTLOOK}

Compared with reinforced concrete and brick-stone construction architecture, wood architecture has many advantages: easy construction, flexible design, being warm in winter and cool in summer, earthquake resistance, and more importantly, being ecological and environment friendly, and energy saving, and besides, sustainment development. Therefore, with the concepts of ecology, environment protection and sustainment development universally accepted by people, the developing history of wood construction architecture has to be reviewed again and the development of wood construction architecture should be put on the agenda [2]. As to Yangzhou, the revival and development of wood construction technology is not just the revival of traditional wood construction technology, but the fundamental way out lies in importing, integrating and absorbing advanced Western modern wood construction technology, and in the combination of modern scientific and traditional experience.

\section{REFERENCES}

[1] Ji Lin, Fan Xuquan. The analysis of Architecture in Yangzhou He Garden [J]. Ancient Architecture and Garden Technology. 2005(9). pages 26.

[2] He Chunrong. Wood Construction Architecture in China [J]. New Architecture, 2005(5). pages 5-7. 